\title{
Concepto restringido de la responsabilidad de mando en el marco jurídico transicional en Colombia, ¿puerta giratoria hacia la intervención de la Corte Penal Internacional?
}

\author{
A Restricted Concept of Command Responsibility \\ in Colombia's Transitional Justice: An Opening for \\ International Criminal Court (ICC) Intervention? \\ Conceito restringido da responsabilidade de \\ mando no marco jurídico transicional na Colômbia, \\ ¿porta giratória para a intervenção da Corte Penal \\ Internacional?
}

Angie Katherine García Atehortúa*

Fecha de recepción: 10 de febrero de 2019

Fecha de aprobación: 18 de marzo de 2019

Doi: $h t t p: / / d x . d o i . o r g / 10.12804 /$ revistas.urosario.edu.co/anidip/a.8490

Para citar este artículo: García Atehortúa, A. K. (2019). Concepto restringido de la responsabilidad de mando en el marco jurídico transicional en Colombia ¿puerta ǵiratoria hacia la intervención de la Corte Penal Internacional? ANIDIP 7, 32-68. Doi: http://dx.doi.org/10.12804/

revistas.urosario.edu.co/anidip/a.8490

\section{Resumen}

Tras la adopción del Acuerdo de Paz en Colombia, se dispuso la creación del Sistema Integral de Verdad, Justicia, Reparación y No Repetición, dentro del cual se contempla el establecimiento de la Jurisdicción Especial para la Paz. Entre las figuras que regulan el procedimiento ante la JEP, la responsabilidad de mando ha suscitado diversos debates en torno a su adecuación con los estándares internacionales y los efectos del concepto restringido adoptado en el marco jurídico transicional. El presente ensayo aborda el análisis sobre la compatibilidad de la definición de responsabilidad del mando contenida en el Acto Legislativo 01 de 2017 y en el Proyecto de Ley Estatutaria de la Administración de Justicia en la Jurisdicción Especial para la Paz con

\footnotetext{
Abogada de la Universidad de Medellín, Colombia. Asesora leģal de la línea de lucha contra la impunidad en la Fundación para la Libertad de Prensa (FLIP). Ex Visitante profesional en la Corte Interamericana de Derechos Humanos Candidata a LL.M in International Human Rights Law en la Universidad de Notre Dame. Correo electrónico: anģiekathe.garcia@gmail.com
} 
los estándares del derecho internacional consuetudinario y del Estatuto de Roma. A partir de ello, se evalúa críticamente qué efectos tendría la aplicación de un criterio restringido de la figura de responsabilidad de mando en el análisis de los casos sometidos ante la JEP, y como ello, podría dar lugar a la intervención de la Corte Penal Internacional e incluso, a la aplicación del principio de jurisdicción universal.

Palabras clave: Responsabilidad de mando, Jurisdicción Especial para la Paz,

Corte Penal Internacional, Estatuto de Roma, principio de complementariedad.

\section{Abstract}

The signature of the Peace Agreement in Colombia implied the creation of the Integral System of Truth, Justice, Reparation, and Non-Repetition, which includes the Special Jurisdiction for Peace (JEP, by its acronym in Spanish). JEP rules regarding command responsibility have raised diverse debates about their consistency with international standards and the effects of the restricted concept adopted into the transitional legal framework. This essay addresses the analysis of the compatibility of the definition of command responsibility of the 2017 Legislative Act 01 and the Draft Law for the Administration of Justice in the Special Jurisdiction for Peace with standards of the customary international law and the Rome Statute. Based on this, the article evaluates the possible consequences of applying a restricted criterion of command responsibility in the analysis of cases submitted to the JEP and how such could lead to the intervention of the International Criminal Court or the universal jurisdiction.

Keywords: Command responsibility, Special Jurisdiction for Peace, International Criminal Court, Rome Statute, principle of complementarity.

\section{Resumo}

Após a adoção do Acordo de Paz na Colômbia se dispôs a criação do Sistema Integral de Verdade, Justiça, Reparação e Não Repetição, dentro do qual se contempla o estabelecimento da Jurisdição Especial para a Paz. Entre as figuras que regulam o procedimento ante a JEP, a responsabilidade de mando tem suscitado diversos debates em torno à sua adequação com os standards internacionais e os efeitos do conceito restringido adotado no marco jurídico transicional. O presente ensaio aborda a análise sobre a compatibilidade da definição de responsabilidade do mando contida no Ato Legislativo 01 de 2017 e no Projeto de Lei Estatutária da Administração de Justiça na Jurisdição Especial para a Paz com os standards do direito internacional consuetudinário e do Estatuto de Roma. A partir disso, avalia-se criticamente que efeitos teria a aplicação de um critério restringido da figura de responsabilidade de mando na análise dos casos submetidos ante a JEP, e como 
isto, poderia dar lugar à intervenção da Corte Penal Internacional e inclusive, À aplicação do princípio de jurisdição universal.

Palavras-chave: Responsabilidade de mando, Jurisdição Especial para a Paz, Corte

Penal Internacional, Estatuto de Roma, princípio de complementariedade.

\section{Introducción}

El 24 de agosto de 2016, el Gobierno de Colombia y las Fuerzas Armadas Revolucionarias de Colombia (en adelante FARC) firmaron el Acuerdo Final para la Terminación del Conflicto y la Construcción de una Paz Estable y Duradera (en adelante, Acuerdo Final o Acuerdo) tras casi cuatro años de conversaciones, y más de 50 años de conflicto armado. El Acuerdo se compone de seis puntos, ${ }^{1}$ dentro de los cuales se dispone la creación del Sistema Integral de Verdad, Justicia, Reparación y No Repetición (punto 5). El Sistema está conformado por la Comisión de Esclarecimiento de la Verdad, la Unidad para la Búsqueda de Personas Desaparecidas, las medidas de reparación integral para la construcción de paz y la Jurisdicción Especial para la Paz (en adelante JEP), siendo este último, el competente de justicia en el proceso transicional.

La implementación del Acuerdo de Paz y el procedimiento ante la JEP se incorpora legislativamente mediante el Acto Legislativo No. 01 de 27 de abril de $2017^{2}$ (en adelante Acto legislativo o Acto), en el que se regula la de responsabilidad del mando, ${ }^{3}$ consagrada en el artículo transitorio 24 . La doctrina de responsabilidad de mando constituye uno de los pilares fundamentales del Acuerdo en materia de justicia, es por ello que de una adecuada aplicación de esta figura depende en gran medida la rendición de cuentas por parte de los máximos responsables y la satisfacción de los derechos de las víctimas a obtener justicia.

Sin embargo, la definición de responsabilidad de mando en el Acto Legislativo ha suscitado diversos debates, ya que incorpora un concepto restrictivo de esta figura, lo que deriva en su falta de adecuación con los estándares de derecho internacional

1 Los 6 puntos del Acuerdo Final son: (1) Hacia un nuevo campo colombiano: Reforma rural integral; (2) Participación política: Apertura democrática para construir la paz; (3) Fin del conflicto; (4) Solución al problema de las drogas ilícitas; (5) Mecanismos de implementación, verificación y refrendación; y (6) Acuerdo sobre las víctimas del conflicto.

2 Acto Leģislativo 1 de 2017: Por medio del cual se crea un título de disposiciones transitorias de la constitución para la terminación del conflicto armado y la construcción de una paz estable y duradera se dictan otras disposiciones (Diario Oficial No. 50.196 de 4 de abril de 2017).

3 La expresión "responsabilidad de mando" se usó originalmente en el contexto militar y eventualmente también se expandió al campo no militar. En este sentido, la expresión responsabilidad superior es más apropiada, ya que incluye a individuos en posiciones no militares. No obstante, en el presente ensayo nos referiremos a la responsabilidad de mando, teniendo en cuenta que es el concepto adoptado en el marco jurídico que implementa el Acuerdo de Paz. 
consuetudinario (en adelante DIC) y del Estatuto Roma (en adelante ER). Al respecto, se ha referido el Fiscal Adjunto de la Corte Penal Internacional (en adelante CPI o Corte) James Stewart (2017) al afirmar que: "[1]a definición de la responsabilidad del mando, contenida en el Acto Legislativo 01, (...), se aparta en algunos aspectos tanto del derecho internacional consuetudinario como del Estatuto de Roma" (p. 24) lo que podría desencadenar que los máximos responsables queden sin castigo.

El presente trabajo busca analizar la compatibilidad de la definición de la responsabilidad del mando en el Acto Legislativo 01 de 27 de abril de 2017 con los estándares del DIC y del ER, ello con el fin de demostrar los efectos de una interpretación restrictiva de la responsabilidad de mando en la activación de la competencia de la CPI y en la aplicación de la jurisdicción universal. Una vez planteado este problema, se proponen criterios para interpretar armónicamente esta figura, de acuerdo con los estándares internacionales y constitucionales. Para desarrollar este planteamiento teórico en primer lugar, se abordará el concepto de responsabilidad de mando en el DIC y en el Derecho Penal Internacional (en adelante DPI); a partir de ahí, se hará un análisis comparativo con la definición adoptada en el artículo 24 del Acto Legislativo, con el fin de determinar los efectos de una aplicación restrictiva de la responsabilidad del mando y ofrecer soluciones interpretativas.

\section{La responsabilidad del mando en el Derecho Internacional}

\subsection{La configuración y evolución de la responsabilidad del mando}

La responsabilidad de mando es una figura por medio de la cual se asigna responsabilidad penal a los militares de alto rango por crímenes de genocidio, crímenes de lesa humanidad y crímenes de guerra cometidos por sus subordinados (Case Matrix Network, 2016). Este concepto tuvo sus orígenes en los manuales militares y ha ido evolucionando a través de la interpretación de las normas del Derecho Internacional Humanitario (en adelante DIH), ${ }^{4}$ concretándose en la práctica de los tribunales penales internacionales (Meloni, 2015).

El primer precedente en el que se aplica esta figura es en el caso Tomoyuki Yamashita, comandante del Ejército Japonés en las Filipinas entre 1944 y 1945. En este caso, la Comisión Militar de los Estados Unidos, como se citó en Olasolo y Canosa (2018), condenó a muerte al comandante por la "omisión en el cumplimiento

$4 \quad$ La doctrina de responsabilidad de mando comienza a configurarse desde la Cuarta Convención de La Haya sobre las Leyes y Costumbres de la Guerra en Tierra de 1907. Para profundizar en este tópico véase: Ilias Bantekas (1999). The Contemporary Law of Superior Responsibility. American Journal of International Law 93(3), 573. 
de su obligación como comandante de controlar las operaciones de los miembros [del ejército] a su cargo, permitiéndoles cometer atrocidades brutales contra el pueblo de los Estados Unidos, sus aliados y dependencias, particularmente Filipinas" (Corte Suprema de Justicia de los Estados Unidos, 1946, p. 114). Posteriormente, algunos casos conocidos por los Tribunales Militares de Estados Unidos en Nuremberg aplicaron la figura de responsabilidad de mando para juzgar a los comandantes militares alemanes. ${ }^{5}$

El Protocolo I Adicional a los Convenios de Ginebra es el primer instrumento internacional que introduce de forma explícita la responsabilidad de mando. El artículo 86.2 sienta las bases de esta doctrina, consagrando que:

[...] la infracción [que] haya sido cometida por un subordinado no exime de responsabilidad penal o disciplinaria, según el caso, a sus superiores, si éstos sabían o poseían información que les permitiera concluir, en las circunstancias del momento, que ese subordinado estaba cometiendo o iba a cometer tal infracción y si no tomaron todas las medidas factibles que estuvieran a su alcance para impedir o reprimir esa infracción.

Por su parte, el Comité Internacional de la Cruz Roja, en el Comentario del Protocolo Adicional a los Convenios de Ginebra (Protocolo I) desarrolla los tres elementos que se deben cumplir para que el superior sea responsable cuando haya una omisión respecto de un delito cometido por un subordinado:

a) El superior en cuestión debe ser el superior de ese subordinado; b) El superior sabía, o tenía información, lo que debería haberle permitido llegar a la conclusión de que se estaba cometiendo una infracción o se iba a cometer; c) El superior no tomó las medidas a su alcance para impedirlo (Boas, Bischoff \& Reid, 2008, p. 152).

Tomando como base la caracterización de la responsabilidad desarrollada en el Protocolo I, los Estatutos del Tribunal Penal Internacional para la ex Yugoslavia (en adelante TPIY) y del Tribunal Penal Internacional para Ruanda (en adelante TPIR) incluyen una disposición específica sobre la responsabilidad de mando.

La responsabilidad de mando, además, tiene carácter consuetudinario. La norma 153 del DIH consuetudinario se refiere a esta figura en los siguientes términos:

5 Al respecto ver: Military Government for Germany, USA, United States of America v. Wilhelm von Leeb et al., Judģment, 28 October 1948, in Trials of War Criminals Before the Nuernberg Military Tribunals Under Control Council Law No. 10, October 1946-April 1949, vol. 11, US Government Printing Office, Washinģton, DC, 1949, pp. 512 ff. ('High Command case'). Disponible en: https://www.leğal-tools.org/doc/c340d7/. 
Norma 153. Los jefes y otros mandos superiores son penalmente responsables de los crímenes de guerra cometidos por sus subordinados si sabían, o deberían haber sabido, que éstos iban a cometer o estaban cometiendo tales crímenes y no tomaron todas las medidas razonables y necesarias a su alcance para evitar que se cometieran o, si ya se habían cometido, para castigar a los responsables (Henckaerts \& Doswald-Beck, 2007, p. 632).

En la práctica adoptada por tribunales penales internacionales fue reconocida como norma consuetudinaria en los juicios seguidos en contra de algunos comandantes militares por los crímenes cometidos por sus subordinados durante la Segunda Guerra Mundial. ${ }^{6}$ También ha sido acogida más recientemente por el Tribunal Europeo de Derechos Humanos al analizar el alcance del artículo 2 del Convención Europea de Derechos Humanos ${ }^{7}$ y por los órganos del Sistema Interamericano de Derechos Humanos al determinar el alcance de las obligaciones de debida diligencia en la investigación de graves violaciones a los Derechos Humanos. ${ }^{8}$

\subsection{La responsabilidad de mando en el Estatuto de Roma}

El artículo 28 del Estatuto de Roma estipula de forma genérica que el superior es responsable frente a los crímenes cometidos por sus subordinados, si incumple con su deber de prevenir, reprimir o someter esa cuestión a la autoridad competente, en virtud del control que ejerce sobre ellos. ${ }^{9}$

El artículo 28 Estatuto de Roma delimita la responsabilidad del superior sobre la base de las obligaciones jurídicas de los jefes militares, a saber: (i) prevenir la comisión de crímenes internacionales por sus subordinados; (ii) reprimir la comisión de dichos crímenes, en el sentido de poner fin a los que se estén cometiendo y castigar

Alģunos casos en los que se aplicó la figura de responsabilidad de mando son: Estados Unidos, Tribunal Militar de Nuremberog, caso Von Leeb (The Highh Command Trial) (párr. 657) y caso List (Hostages Trial) (párr. 658); Estados Unidos, Corte Suprema, caso Yamashita (párr. 659); Reino Unido, Tribunal Militar de Wuppertal, caso Rauer (párr. 656); Tribunal Militar Internacional de Tokyo, caso de los Mayores Criminales de Guerra (párrs. 693 a 700) y Caso Toyoda. En este mismo, sentido el TPIY en el caso Mucić et al. ("Čelebići").

7 Ver: Corte Europea de Derechos Humanos. Caso Jelic c. Croacia, Sentencia de fondo. Aplicación no. 57856/11, 12 de junio de 2014, párrs. 88-90.

8 Al respecto ver: Caso de la Masacre de Pueblo Bello Vs. Colombia. Fondo, Reparaciones y Costas, párr. 143; Caso de la "Masacre de Mapiripán" Vs. Colombia. Fondo, Reparaciones y Costas, párr. 110; y caso Masacre de Santo Domingo Vs. Colombia. Solicitud de Interpretación de la Sentencia sobre Excepciones Preliminares, Fondo, Reparaciones y Costas. Sentencia de 19 de agosto de 2013. Serie C No. 263. 162.

9 Para ampliar este concepto ver: CPI, SPI II, Fiscal c. Dominic Onģwen, "Decision on the confirmation of charģes aģainst Dominic Onģwen", ICC-02/04-01/15-422-Red, 23/03/2016, párrs. 45 y 146; SCP I, Fiscal c. Laurent Gbaģbo, ICC02/11-01/11-656-Red, cit., párr. 262; SCP II, Fiscal c. Jean-Pierre Bemba Gombo, "Decision Pursuant to Article 61(7)(a) and (b) of the Rome Statute on the Charges of the Prosecutor Against Jean-Pierre Bemba Gombo", ICC-01/05-01/08-424, 15/06/2009, párr. 405. 
a los subordinados que hayan estado involucrados en los mismos, y (iii) enviar la cuestión a las autoridades competentes cuando no se tenga la facultad jurídica para castigar (Olasolo, 2013, p. 767). Sin embargo, estas obligaciones no pueden ser analizadas de forma aislada, puesto que, si se omite el cumplimiento de alguna de ellas, se podría atribuir responsabilidad al superior en virtud del artículo 28 del Estatuto de Roma (Acevedo, 2007); esto significa, que "la responsabilidad penal por omitir el deber de prevenir no puede ser eximida por el cumplimiento de los deberes de reprimir y enviar la cuestión a la autoridad competente" (Olasolo \& Canosa, 2018, p. 453).

Con el fin de determinar los elementos específicos que definen la responsabilidad de mando resulta esencial aproximarnos a la interpretación del artículo 28 del Estatuto de Roma desarrollada en el caso Jean-Pierre Bemba Gombo del 15 de junio de 2009. ${ }^{10}$ En este caso, la CPI sostuvo que deberán cumplirse con los siguientes requisitos para que un superior incurra en responsabilidad conforme al artículo 28:

(a) el sospechoso debe ser un superior militar, o una persona que actúe efectivamente como tal; (b) el sospechoso debe tener un mando y control efectivo, o una autoridad y control efectivo sobre las fuerzas (subordinados) que cometieron uno o más de los delitos previstos en los artículos 6 al 8 del Estatuto; (c) los delitos cometidos por sus fuerzas (subordinados) resultaron de la omisión del sospechoso de ejercitar un adecuado control sobre las mismas; (d) el sospechoso conocía o debía conocer las circunstancias vigentes al momento, o ha debido saber, que las fuerzas (subordinados) estaban cometiendo o iban a cometer uno o más de los delitos previstos en los artículos 6 al 8 del Estatuto; y (e) el sospechoso no adoptó las medidas necesarias y razonables a su disposición para evitar o castigar la comisión de tales delitos, o dejó de informar sobre el asunto a las autoridades competentes para su investigación y enjuiciamiento" (párr. 407).

10 Sobre este caso se refirió Kai Ambos, en el periódico en Semana, el 15 de junio de 2018, en los siguientes términos: "El 21 de marzo de 2016, una Sala de primera instancia de la CPI condenó al político congoleño Jean Pierre Bemba por la comisión de crímenes de ơuerra (asesinato, violación y saqueo) y crímenes de lesa humanidad (asesinato y violación) realizados por sus tropas en la República Centroafricana en los años 2002 y 2003, invocando la fiğura de responsabilidad del superior. (...)”. El 8 de junio de 2018, Bemba fue absuelto por la Sala de Apelaciones de la CPI, basando sus argumentos en consideraciones probatorias y en la interpretación restrictiva del superior (2018). 
Estos requisitos pueden ser acotados a la satisfacción de tres elementos: (a) la existencia de una relación superior-subordinado; (b) la omisión por el superior de su obligación jurídica de adoptar todas las medidas razonables y necesarias a su disposición para prevenir, reprimir o someter a la autoridad competente los crímenes internacionales de sus subordinados (elemento objetivo), y (c) el conocimiento que el superior tenía o debiera haber tenido de dichos crímenes internacionales (elemento subjetivo) ${ }^{11}$ (Werle, 2011). Dada la importancia de estos elementos, más adelante se abordará un análisis comparativo de los mismos en relación con el concepto de responsabilidad de mando del artículo 24 transitorio del Acto Legislativo.

\section{La responsabilidad de mando en el Marco Jurídico Transicional}

La responsabilidad de mando como régimen de imputación especial fue incluido dentro del marco jurídico transicional en varios puntos del Acuerdo Final de Paz, en el artículo 24 del Acto Legislativo 01 de 2016 y en los artículos 67 y 68 del Proyecto de Ley número 008 de 2017 Senado - 016 de 2017 Cámara, "Estatutaria de la Administración de Justicia en la Jurisdicción Especial para la Paz" (en adelante Proyecto de Ley Estatutaria de la JEP o PLE). ${ }^{12}$

Antes de su incorporación en el ordenamiento jurídico colombiano como parte de la implementación del Acuerdo, la responsabilidad de mando había sido discutida y fue incluida por primera vez en el Acuerdo sobre las Víctimas del Conflicto, aprobado el 15 de diciembre de 2015 como parte de los aspectos relacionados con el tratamiento penal que recibirían los actores armados en el postconflicto. Así, en cuanto los elementos definitorios de la responsabilidad penal, en el parágrafo 44 del acápite de la JEP se hacía referencia al tratamiento diferenciado al que serían sometidos los agentes del Estado con apego a las normas del DIH. Por otra parte, se dispuso que para definir la responsabilidad penal de los integrantes de las FARC se tendría "como referente jurídico el Derecho Internacional Humanitario, el Derecho Internacional de los Derechos Humanos y el Derecho Internacional Penal" (Oficina del Alto comisionado para la Paz, 2015, p. 39).

Véase, entre otros: Prosecutor vs. Delalic y otros (Celebici case), caso IT-96-21-T, sentencia del 16 de noviembre de 1998, parágrafos 354, 370, 395, 773, 774.

12 A la fecha de redacción de este ensayo, el PLE se encuentra pendiente del trámite leơislativo de sanción presidencial y de promulģación para que pueda ser considerado ley de la República. Al tratarse de una ley estatutaria, la Corte Constitucional de Colombia realizó un control automático de constitucionalidad en la Sentencia C-080 de 2018. Referencia: Expediente RPZ-010. Magistrado Sustanciador: Antonio José Lizarazo Ocampo. Bogotá D.C., 15 de agosto de dos mil dieciocho (2018). 
Sobre la imputación de responsabilidad a los mandos de la fuerza pública y los comandantes guerrilleros por actos de sus subordinados, se señaló que ésta deberá fundarse en: (i) el control efectivo de la respectiva conducta; (ii) en el conocimiento basado en la información a su disposición antes, durante y después de la realización de la respectiva conducta; y (iii) los medios a su alcance para prevenirla, y en adoptar las decisiones correspondientes, que en el caso de miembros de la fuerza pública consisten en promover las investigaciones procedentes (Oficina del Alto comisionado para la Paz, 2015).

Después del triunfo del 'no' en el plebiscito por la paz, se aprobó el Acuerdo Final el 12 de noviembre de 2016 en el que se introdujeron algunas modificaciones propuestas por los voceros del 'no.13 Respecto de la responsabilidad de los mandos de las FARC, se adiciona un inciso en el que se indica que deberá entenderse por control efectivo de la respectiva conducta, “(...) la posibilidad real que el superior tenía de haber ejercido un control apropiado sobre sus subalternos, en relación con la ejecución de la conducta delictiva, tal y como se establece en el derecho internacional"14 (Acuerdo Final, 2016, p. 164). En cuanto a los miembros de la Fuerza Pública, se suprimió toda mención al significado de control efectivo.

Las sucesivas modificaciones y supresiones en la regulación de la responsabilidad de mando generaron preocupaciones por parte de diversos sectores ${ }^{15}$ entre ellos, la Fiscalía de la CPI. En el Informe del 2016 sobre las actividades de examen preliminar de la situación en Colombia, la Fiscalía de la CPI expresó que deberá tenerse en consideración "si existe alguna laguna sustantiva en las leyes aplicadas por las autoridades competentes de la Jurisdicción Especial para la Paz, como las relativas a la responsabilidad del superior" (p. 257). Estas observaciones fueron reiteradas en el Informe de Colombia sobre las actividades de examen preliminar del 5 de diciembre de 2018 (párr. 156). Posteriormente, la Fiscal Fatou Bensouda (2017) manifestó que "[a]unque el concepto de responsabilidad de mando aparece

13 El 2 de octubre de 2016 se llevó a cabo a plebiscito sobre el Acuerdo de paz del 24 de aģosto de 2016 por medio del cual se pretendía la refrendación para aprobar los acuerdos entre el ģobierno de Colombia y la guerrilla de las Fuerzas Armadas Revolucionarias de Colombia (FARC). Sin embarģo, la mayoría de los votantes rechazaron el Acuerdo con las FARC.

14 La redacción tal como aparece fue rectificada mediante el comunicado conjunto \# 16 del 24 de noviembre de 2016, en el que las Delegaciones del Gobierno Nacional y de las FARC-EP modifican lo siguiente: "Se entiende por control efectivo de la respectiva conducta, la posibilidad real que el superior tenía de haber ejercido un control apropiado sobre sus subalternos, en relación con la ejecución de la conducta delictiva, tal y como se establece en el derecho internacional, tal y como indica el artículo 28 del Estatuto de Roma".

15 Al respecto ver: Vivanco está "decepcionado" por cambio en Acuerdo de Paz. El Tiempo. 25 de noviembre de 2016. también: R. Uprimny y D. Guiza, Reflexiones sobre la reforma constitucional que crea la Jurisdicción Especial para la paz y regula el tratamiento especial a la Fuerza Pública, Centro de Estudios de Derecho, Justicia y Sociedad (Dejusticia), 13 de febrero de 2017. 
claramente definido en el Estatuto de Roma, observ[aba] con cierta preocupación que en la versión final del acuerdo de paz se ha eliminado toda referencia directa al correspondiente artículo 28 del estatuto". Finalmente, a pesar de las observaciones señaladas, el artículo 24 del Acto Legislativo incorpora requisitos adicionales y diferentes a los contemplados en el derecho internacional -definición restrictiva, lo que podría derivar en la impunidad de los delitos cometidos bajo esta modalidad y, en consecuencia, en el incumplimiento de la obligación internacional de los Estados de investigar, juzgar y sancionar los crímenes internacionales aún en contextos de transición. ${ }^{16}$

\subsection{La definición de responsabilidad de mando en el Acto Legislativo 01 de 2017}

Entre los criterios que rigen el procedimiento ante la JEP está la figura de la responsabilidad de mando, contemplada en el artículo 24 transitorio del Acto Legislativo 01 de 2017. En dicho artículo no solo se define el concepto de responsabilidad de mando, sino que además se señalan cuáles son los eventos en los que se considera que existe mando y control efectivo del superior, así:

[...] La determinación de la responsabilidad del mando no podrá fundarse exclusivamente en el rango, la jerarquía o el ámbito de jurisdicción. La responsabilidad de los miembros de la Fuerza Pública por los actos de sus subordinados deberá fundarse en el control efectivo de la respectiva conducta, en el conocimiento basado en la información a su disposición antes, durante, o después de la realización de la respectiva conducta, así como en los medios a su alcance para prevenir que se cometa o se siga cometiendo la conducta punible, siempre y cuando las condiciones fácticas lo permitan, y de haber ocurrido, promover las investigaciones procedentes. Se entenderá que existe mando y control efectivo del superior militar o policial sobre los actos de sus subordinados, cuando se demuestren las siguientes condiciones concurrentes:

a) Que la conducta o las conductas punibles hayan sido cometidas dentro del área de responsabilidad asignada a la unidad bajo su

16 La Corte Constitucional de Colombia declara exequible el artículo 24 del Acto Legíslativo 01 de 2017 mediante la Sentencia C-674 de 2017. Referencia: Expediente RPZ-00. Maģistrado Sustanciador: Luis Guillermo Guerrero Pérez, Bogotá D.C. Recuperado de http://www.corteconstitucional.gov.co/relatoria/2017/C-674-17.htm 
mando según el nivel correspondiente y que tengan relación con actividades bajo su responsabilidad;

b) Que el superior tenga la capacidad legal y material de emitir órdenes, de modificarlas o de hacerlas cumplir;

c) Que el superior tenga la capacidad efectiva de desarrollar y ejecutar operaciones dentro del área donde se cometieron los hechos punibles, conforme al nivel de mando correspondiente; $y$

d) Que el superior tenga la capacidad material y directa de tomar las medidas adecuadas para evitar o reprimir la conducta o las conductas punibles de sus subordinados, siempre y cuando haya de su parte conocimiento actual o actualizable de su comisión (Acto Legislativo 01, 2017).

Como puede extraerse, en el texto precitado solo se hace mención expresa a los miembros de la Fuerza Pública, lo cual suponía una laguna jurídica en la imputación de responsabilidad de mando a los jefes de las FARC; sin embargo, esta situación se vería en parte subsanada en el Proyecto de Ley Estatutaria de la JEP, ${ }^{17}$ cuyo artículo $67^{18}$ regula la responsabilidad de los mandos de las FARC-EP, con algunas diferencias respecto del tratamiento que reciben los miembros de la Fuerza Pública.

Las dos diferencias principales entre la responsabilidad de mando en el artículo 67 del PLE y en el artículo 24 del Acto Legislativo 01 de 2017, es que esta última resulta más estricta y por lo tanto más restrictiva en cuanto: (i) exige el cumplimiento de condiciones concurrentes para probar la existencia de control efectivo; y (ii) condiciona el cumplimiento de la obligación de prevenir a las posibilidades del superior de acuerdo con las condiciones fácticas. Por otra parte, en cuanto a la responsabilidad de los mandos de las FARC, se indica que deberá interpretarse el control efectivo

17 A la fecha de redacción de este ensayo, el PLE se encuentra pendiente del trámite leģislativo de sanción presidencial y de promulgación para que pueda ser considerado ley de la República. Al tratarse de una ley estatutaria, la Corte Constitucional de Colombia realizó un control automático de constitucionalidad en la Sentencia C-080 de 2018. Referencia: Expediente RPZ-010. Maģistrado Sustanciador: Antonio José Lizarazo Ocampo. Bogotá D.C., 15 de aģosto de dos mil dieciocho (2018).

18 Proyecto de Ley Estatutaria de la JEP: Artículo 67. Responsabilidad de los mandos de las FARC-EP. “La responsabilidad de los mandos de las FARC-EP por los actos de sus subordinados deberá fundarse en el control efectivo de la respectiva conducta, en el conocimiento basado en la información a su disposición antes, durante y después de la realización de la respectiva conducta, así como en los medios a su alcance para prevenirla, y de haber ocurrido adoptar las decisiones correspondientes. La responsabilidad del mando no podrá fundarse exclusivamente en el rangoo o la jerarquía" (Proyecto de Ley Estatutaria JEP, art. 67).

Se entiende por control efectivo de la respectiva conducta, la posibilidad real que el superior tenía de haber ejercido un control apropiado sobre sus subalternos, en relación con la ejecución de la conducta delictiva, tal y como se establece en el Derecho Internacional. 
“(...) tal y como se establece en el derecho internacional", lo que difiere sustancialmente de la exigencia de condiciones concurrentes para probar el control efectivo aplicable a los mandos de la fuerza pública.

Estas diferencias resultan problemáticas, puesto que es posible que, en el trámite ante la JEP, los miembros de las FARC soliciten la aplicación preferente del artículo 24 del Acto Legislativo por ser más favorable a la hora de determinar el alcance de la responsabilidad de mando, al exigir la concurrencia de requisitos para probar el control efectivo, lo que implicaría que si al menos una de ellas no se cumple se eximirían de responsabilidad penal. Así, en virtud del principio de favorabilidad, los mandos de las FARC podrían exigir que, en la imputación de responsabilidad de mando se aplique el concepto más restringido de esta figura, incluso si este resulta incompatible con los estándares internacionales. ${ }^{19}$

Además de estos aspectos, el concepto de responsabilidad del mando del artículo 24 es incompatible con los estándares internacionales por las siguientes razones: (i) exige el control efectivo del superior sobre la conducta y no sobre los subordinados a su mando; (ii) demanda la concurrencia de cuatro condiciones para que pueda configurarse el control efectivo; (iii) requiere que la conducta punible haya sido cometida dentro del área de responsabilidad asignada a la unidad bajo su mando; (iv) exige capacidad legal y material del superior, excluyendo aquellos casos en los que solo exista capacidad material; (v) no define el alcance de la expresión "medios a su alcance" siendo una expresión vaga y ambigua; y (vi) establece como requisitos adicional el conocimiento actual o actualizable por parte del superior, desconociendo el estándar de conocimiento inferido. Estos criterios restrictivos serán analizados en relación con los elementos de la responsabilidad de mando en el artículo 28 del ER a continuación.

\subsubsection{Relación superior-subordinado: mando o control efectivo sobre los subordinados}

El artículo 24 del Acto Legislativo 01/2017 prevé que la responsabilidad de mando deberá fundarse en el control efectivo que tenga el superior sobre la conducta de su subordinado. Esta concepción difiere del DIC y del artículo 28 del Estatuto de Roma, puesto que, de acuerdo con los estándares internacionales, solo se exige que el jefe ejerza su mando o control efectivo sobre los subordinados que cometen los crímenes, no sobre su conducta criminal (Bensouda, 2017). Es por ello que una redacción en estos términos resulta limitada y contraria al objeto de la figura de responsabilidad de mando.

19 Siendo que el concepto de responsabilidad de mando del Acto leģislativo es el más problemático, el ensayo se centrara el análisis de sus elementos. 
El requisito de control efectivo del superior sobre la conducta del subordinado implicaría trasladar criterios de otras formas de autoría en las que se exige el dominio del hecho como es el caso de la autoría mediata, modalidad de autoría que difiere de la de responsabilidad de mando, al configurarse como un delito de omisión propia o, en el caso del incumplimiento de la obligación de prevenir, como una forma de participación por complicidad dolosa o imprudente (Olasolo, 2013). En palabras de la Fiscal de la CPI, "el requisito de que el superior controle la conducta parecería necesariamente sugerir algún tipo de restricción sobre el alcance de la conducta del subordinado por la que el superior podría ser responsabilizado" (2017). ${ }^{20}$ De esta forma, la interpretación que se haga de este requisito no deberá limitar la responsabilidad que efectivamente pudieran tener los mandos militares por las conductas de sus subordinados incluso cuando no tengan dominio de ellas.

Por otra parte, el artículo 24 requiere la concurrencia de cuatro condiciones para que pueda configurarse el control efectivo. "Tal exigencia de que concurran requisitos formales y materiales, para comprobar la responsabilidad del mando, desconoce el DPI consuetudinario", ya que si bien hay criterios que pueden conducir a probar la existencia del control efectivo, estos son puramente indicativos y no se requiere su concurrencia de manera obligatoria (Uprimny \& Güiza, 2017, pp. 18-19). Al respecto, se expondrán algunas breves consideraciones.

\subsubsection{Conductas punibles cometidas dentro del área de responsabilidad}

De acuerdo con el artículo 24, una de las condiciones del control efectivo es que la conducta punible haya sido cometida dentro del área de responsabilidad asignada a la unidad bajo su mando según el nivel correspondiente y "que tengan relación con actividades bajo su responsabilidad". Esta condición está relacionada directamente con el requisito del literal c del artículo 24, en el que se exige capacidad efectiva del superior para desarrollar y ejecutar operaciones dentro de esa área. No obstante, estas condiciones no son requisitos para demostrar el control efectivo del superior, ni en el DIC ni en el Estatuto de Roma.

La evaluación de tales condiciones resulta innecesaria a la hora de probar el control efectivo que tenga el superior, puesto que podría desconocer circunstancias en las que el superior puede materialmente dar órdenes de desplazamiento a áreas fuera de su zona geográfica de influencia y aun así conservar el control efectivo sobre sus subordinados (Olasolo \& Canosa, 2018, p. 453).

20 El Estudio de Derecho Internacional Humanitario consuetudinario del CICR señala que al efectuar interpretación de la norma 153, algunos juristas han procurado describir los alcances del control sobre el subordinado a través del control sobre sus acciones, pero esto no significa que se establezca un requisito jurídico adicional (CICR, citado por Bensouda, 2017). 
Seguir esta lógica implicaría que en casos como el de Bemba no hubiera sido posible que la Sala de Primera Instancia de la CPI lo condenara por crímenes cometidos por sus tropas en la República centroafricana, donde no tenía mando legal pero sí control material sobre las tropas que allí operaban (Uprimny \& Güiza, 2017). En consecuencia, circunscribir la responsabilidad del superior a la comisión de crímenes en el área que le haya sido formalmente asignada tiene un efecto incompatible con el DPI, por cuanto ignora que no hay límites geográficos o temporales a la autoridad que un superior ejerce sobre sus subordinados ${ }^{21}$ (Klamberg, 2017).

\subsubsection{Capacidad leģal y material del superior}

En primer lugar, el artículo 24 transitorio dispone que "la determinación de la responsabilidad del mando no podrá fundarse exclusivamente en el rango, la jerarquía o el ámbito de jurisdicción", apartado que resulta coherente con los estándares internacionales, ya que la existencia del control efectivo del superior sobre sus subordinados involucra la capacidad material del superior para prevenir crímenes futuros o castigar crímenes pasados cometidos por sus subordinados ${ }^{22}$ (Bensouda, 2017).

Sin embargo, como parte de las condiciones concurrentes del control efectivo se exige que el superior tenga capacidad legal y material de emitir órdenes, de modificarlas o de hacerlas cumplir. Partiendo de esta premisa, un superior sólo podría ser responsable si además de ser designado formalmente, tiene capacidad material sobre sus subordinados, lo que excluye de responsabilidad penal a los superiores de facto, es decir, aquellos que ostentan mando, pero carecen de un nombramiento institucional.

Al interpretar la noción de persona que "actúa efectivamente como jefe militar", la CPI se refiere a aquellos que no son elegidos por ley para llevar a cabo esa función, pero la desempeñan de facto $^{23}$ (Kiss); por lo tanto, es una categoría mucho más amplia que puede incluir, por ejemplo, oficiales de policía que han sido asignados al mando de unidades de policía armadas, aunque no sean militares de alto rango (Fenrick, 1999, p. 517).

\footnotetext{
21 Véase, por ejemplo, Schabas (2016). The International Criminal Court: A Commentary on the Rome Statute (2a Edición). Oxford: OUP. pág. 613; Vetter (2000). Command responsibility of non-military superiors in the International Criminal Court (ICC). Yale Journal of International Law 25(1), pág. 120. 
Por ende, con el fin de que Colombia cumpla con sus obligaciones internacionales, es necesario que este requisito sea interpretado en tal sentido que se entienda por un jefe militar o superior no solamente aquel que ostenta el mando por designación oficial sino "quien tiene poder o autoridad, ya sea de jure o de facto, para prevenir el crimen de un subordinado o castigar a los autores del crimen una vez que fue cometido" (ICTY, 2001, párr. 192).

\subsubsection{La omisión de adoptar medidas razonables y necesarias para prevenir, reprimir o enviar a la autoridad competente los crímenes de sus subordinados (elemento objetivo)}

Este elemento se refiere a la naturaleza de la responsabilidad penal en el artículo 28 del ER, en el que se indica que se trata de un delito de omisión que consiste, a nivel objetivo, en el incumplimiento por parte del superior de supervisar apropiadamente a los subordinados ${ }^{24}$ (Wu \& Kang, 1997). En términos generales, este requisito supone que, "[l]os jefes y otros mandos superiores son penalmente responsables si (...) no tomaron todas las medidas razonables y necesarias a su alcance para evitar que se cometieran o, si ya se habían cometido, para castigar a los responsables" (Henckaerts \& Doswald-Beck, 2007, p. 632).

Ahora bien, el artículo 24 transitorio del Acto Legislativo dispone que la responsabilidad de mando deberá fundarse, además, "en los medios al alcance del superior para prevenir que se cometa o se siga cometiendo la conducta punible, siempre y cuando las condiciones fácticas lo permitan, y de haber ocurrido, promover las investigaciones procedentes". Esta redacción puede resultar problemática sino se interpreta "medios a su alcance" en el sentido de la expresión "medidas necesarias y razonables" del artículo 28 del ER.

La jurisprudencia internacional ha entendido como medidas 'necesarias' aquellas apropiadas para que el superior cumpla su obligación de prevenir o castigar según las circunstancias imperantes en ese momento; y como 'razonables' las medidas que el superior estaba en condiciones de adoptar en esas circunstancias"25 (TPIR, 2001, parág. 4). Por consiguiente, para mantener la compatibilidad con el Derecho Internacional, el superior deberá entenderse responsable de interpretar estas medidas de la forma más amplia posible.

\footnotetext{
24 “[...] la responsabilidad penal del superior por los crímenes de sus subordinados no se limita solamente a la autoría o participación activa de aquellos, sino que también comprende la comisión por omisión" TPIY, Oric, TC II, Judgement, Case No. IT-03-68-T, 30 de junio de 2006, parág. 300.

25 TPIY, Halilovic, AC, Appeal Judģement, Case No. IT-01-48-A, 16 de octubre de 2007, parág. 63; confirmada en TPIY, Oric, AC, Appeal Judgement, Case No. IT-03-68-A, 3 de julio de 2008, parág. 177.
} 
$\mathrm{Al}$ analizar este elemento, es necesario precisar que el artículo 24 no exige un nexo de causalidad entre la omisión del superior y los delitos de sus subordinados, como el que se requiere en el artículo 28 del ER. No obstante, la redacción de este elemento corresponde a la regulación prevista en los estatutos y jurisprudencia del Tribunal Internacional para la Ex Yugoslavia (o TIPY), el Tribunal Internacional para Ruanda (en adelante TIPR) y la Corte Especial para Sierra Leona (o CESL), en las que no se exige un vínculo de causalidad. ${ }^{26}$ Por lo tanto, la ausencia de este requisito dentro del artículo 24 no resulta problemática, puesto que no es excluyente de atribución de este tipo responsabilidad por delitos de omisión propia, pero descarta "la configuración de la responsabilidad del superior como un supuesto de complicidad por omisión dolosa o imprudente, puesto que esta última requiere que el incumplimiento del superior tenga un efecto favorecedor (nexo de causalidad) de la conducta punible de los subordinados" (Olasolo \& Canosa, 2018, p. 494).

\subsubsection{Conocimiento de la comisión de conductas punibles (elemento subjetivo)}

Respecto del elemento subjetivo, el Acto Legislativo exige el "conocimiento basado en la información a su disposición antes, durante o después de la realización de la respectiva conducta" y el "conocimiento actual o actualizable de su comisión". Sin embargo, no se incluye el estándar "hubiere debido saber" del artículo 28.a.i del ER, y además agrega la expresión "actual o actualizable" que resulta ambigua y restrictiva a la hora de determinar la responsabilidad del superior.

De acuerdo con el DIC "los jefes militares y otros superiores son penalmente responsables si sabían o tenían razones para saber que los subordinados se disponían a cometer (o ya habían cometido) los crímenes"27 (Bensouda, 2017). Respecto de la expresión "sabían", desarrollada en el ER como "hubiere sabido" y que se refiere la existencia de conocimiento efectivo, ${ }^{28}$ en el artículo 28 del Estatuto también se

26 A pesar de que la sentencia de primera instancia del TIPY en el caso Delalic exiģió la existencia de un nexo causal entre la no omisión del deber de prevenir del superior y la comisión de los crímenes internacionales por los subordinados, la Sala de Apelaciones del TIPY ha rechazado esta interpretación en las sentencias de apelación en el caso Blaskic (párr. 77).

27 Véase también, Fiscal c. Čelebići, ICTY-96-21-A, (Sentencia de apelación), 20 de febrero de 2001, paráğs. 222, 241.

28 La expresión "hubiere sabido" del artículo 28 del Estatuto de Roma requiere la existencia de conocimiento efectivo que "puede definirse como el ser consciente de que los crímenes relevantes habían sido cometidos o estaban por ser cometidos" (TESL, 2012, paraģ. 497). Sin embaro̧o, "el conocimiento efectivo debe ser probado, pero puede ser inferido por evidencias circunstanciales, tales como la posición del acusado" (Ambos, 1999). En el caso Bemba, la CPI señala como factores circunstanciales "los actos prohibidos tuvieron luģar, el tipo y cantidad de fuerzas involucradas, los medios de comunicación disponibles, el modus operandi de actos similares, el alcance y la naturaleza de la posición del superior y su responsabilidad en la estructura jerárquica, la ubicación del jefe militar en el momento y la ubicación geográfica de los actos. También podrá probarse que sabía si, 'a priori, [un jefe militar] forma parte de una estructura orģanizada 
dispone que, en razón de las circunstancias del momento, el comandante "hubiere debido saber" que las fuerzas estaban cometiendo esos crímenes o se proponían cometerlos. ${ }^{29}$ Este elemento en la responsabilidad de mando se aproxima a la imposición de responsabilidad objetiva por negligencia aplicable cuando el superior incumple su deber de permanecer constantemente informado de las acciones de sus subordinados (TPIY, 1998).

"La práctica confirma que la responsabilidad no se limita a situaciones en las que el jefe o superior jerárquico tiene un conocimiento real de los crímenes cometidos o que iban a cometer sus subordinados, sino que basta un conocimiento inferido" (CICR, 2007, p. 635). En virtud de lo anterior, la expresión "conocimiento actual o actualizable" es incongruente con el estándar de conocimiento inferido, pues excluye la posibilidad de juzgar a los superiores que hayan omitido su deber de mantenerse informados de las actividades de sus subordinados relacionadas con la preparación o comisión de crímenes internacionales. ${ }^{30}$

\section{La interpretación restrictiva del artículo transitorio $24^{\circ}$ y la activación de la competencia de la Corte Penal Internacional}

Para determinar los efectos de una interpretación restrictiva de la responsabilidad de mando en los procesos ante la JEP es fundamental valorar el alcance del principio de complementariedad. Este principio es desarrollado en el preámbulo y en los artículos 1, 17, 18, 19 y 20 del ER; tiene como fundamento un sistema de jurisdicción compartida entre la CPI y las jurisdicciones nacionales (Olasolo, 2011, p. 168). En este sentido, la aplicación de la complementariedad se basa en la idea de que instituciones nacionales e internacionales comparten responsabilidad en la investigación y juzgamiento de crímenes internacionales; por lo tanto, la CPI goza de un derecho independiente de evaluación (derecho de consideración)

con sistemas establecidos de monitoreo y denuncia'. Por consiguiente, la Sala considera que estos factores son instructivos a los efectos de realizar una determinación acerca de si el superior sabía en el marco del Artículo 28 del Estatuto" (paráģ. 431)

29 “El estándar 'tenía razones para saber' no exige que se pruebe conocimiento efectivo, ya sea explícito o circunstancial. Tampoco exigge que la Sala tenga por probado que el acusado sabía efectivamente que se habían cometido o se iban a cometer crímenes. Solamente exioge que la Sala esté satisfecha de que el acusado tenía 'alģuna información ģeneral en su poder, que lo habría puesto sobre aviso de posibles actos ilícitos por parte de sus subordinados'" PIR, Baģilishema, AC, Appeal Judģement, Case No. ICTR95-1A-A, 3 de julio de 2002, paráģ. 28. Confirmada en TPIR, Nahimana et al., AC, Appeal Judgoement, Case No. ICTR-99-52-A, 28 de noviembre de 2007, parág. 791 y TPIR, Baģilishema, AC, Appeal Judogement, Case No. ICTR-95-1A-A, 3 July 2002, parág. 42; con referencia a TPIY, Mucic et al. (“Čelebići”), AC, Appeal Judgement, Case No. IT-96-21-A, 20 February 2001, parág. 238.

30 Ver: CPI. Decisión de confirmación de cargos, ICC-01/04-01/06-803-tEN, The Prosecutor v. Thomas Lubanģa Dyilo, Sala de Cuestiones Preliminares I, 7 de febrero de 2007, párr. 434. S 
sobre la situación y las opciones de justicia adoptadas en el contexto nacional (Stahn, 2019, p. 195).

La CPI ha indicado que el principio de complementariedad tiene dos dimensiones: "(i) la prueba de admisibilidad, es decir, la evaluación de la existencia de los procedimientos nacionales y su autenticidad, que es una cuestión judicial; y (ii) el concepto de complementariedad positiva, que se refiere a una política proactiva de cooperación dirigida a la promoción de procedimientos nacionales" (p. 4 y 5). ${ }^{31}$ Este último implica que más allá de entender la jurisdicción de la CPI como última ratio, el papel de la Corte se concentra, además, en reforzar la capacidad de las autoridades nacionales para investigar y enjuiciar los delitos ya cometidos (Lam, 2014, p. 8). ${ }^{32}$

Colombia es un Estado parte en el Estatuto de Roma desde el 1 de noviembre de $2002,{ }^{33}$ y desde entonces, la Fiscalía de la CPI ha tenido un rol destacado en el seguimiento de los procesos de paz con los paramilitares en 2005 (El Tiempo, 2010) y con las FARC (en 2016), cooperando en el fortalecimiento de los mecanismos de justicia transicional a través de recomendaciones para la adecuada implementación del componente de justicia, de acuerdo con las obligaciones internacionales. ${ }^{34}$ Por otro lado, la Fiscalía de la CPI viene haciendo un examen preliminar de la situación de Colombia desde junio de 2004, ${ }^{35}$ en relación con los presuntos homicidios

31 En octubre de 2010, el Fiscal manifestó en un documento borrador que circuló que la "complementariedad positiva" se basa en el preámbulo y el artículo 93 (10) del Estatuto de Roma, destacando que se trata de una noción que debe diferenciarse del principio de complementariedad contenido en el artículo 17 del Estatuto (ICC-OTP Draft Policy Paper on Preliminary Examinations, par. 93). Además, manifestó que "en todas las fases del examen preliminar, y de manera consistente con su política de complementariedad positiva, la Oficina buscará estimular, cuando sea viable, investiģaciones y acusaciones nacionales genuinas por parte de los Estados concernidos, y cooperar y proporcionar asistencia a esos Estados en desarrollo del artículo 93(10) del Estatuto". (ICC-OTP Draft Policy Paper on Preliminary Examinations, par. 94. Expresó que su Oficina seguía este enfoque con Colombia. Id., par. 97.

Véase: STAHN, C., \& SLUITER, G. (coords.) (2009). The emerģing practice of the International Criminal Court Leiden: Brill; CROSS, M.E., \& WILLIAMS, S. (2010). Recent Developments at the ICC: Prosecutor vs Germain Katanģa and Mathieu Nģudjolo Chui: A Boost for Co-operative Complementarity? Human Rights Law Review 10.

33 Colombia ratificó el Estatuto de Roma el 5 de agosto de 2002, respecto de los crímenes de lesa humanidad y ģenocidio. El tratado entró en viģor el 1 de noviembre de 2002. Con respecto a los crímenes de ģuerra, la Corte puede ejercer su jurisdicción sobre los crímenes cometidos a partir del 1 de noviembre de 2009.

34 “(...) [S]emanas después de que la Corte Constitucional de Colombia se pronunciara en mayo de 2006 sobre la constitucionalidad de la Ley de Justicia y Paz (pieza clave del proceso de desmovilización de los grupos paramilitares), la Fiscalía de la CPI anunció que desde el año 2005 venía desarrollando un examen preliminar sobre la situación en Colombia. Al año siguiente, en octubre de 2007, y posteriormente en agosto de 2008, el entonces Fiscal Jefe de la CPI, Luis Moreno-Ocampo, realizó importantes visitas al país (...)" (Olasolo, 2014, p. X).

El 18 de octubre de 2017, la Oficina de la Fiscalía de la CPI remitió un escrito de amicus curiae ante la Corte Constitucional de Colombia en la sentencia (Sentencia C-674 de 2018) en la que se hizó el estudio de la constitucionalidad del Acto Leģislativo 01 de 2017 por medio del cual se inicia la implementación leo̧islativa del Acuerdo Final.

35 Sobre las actividades de examen preliminar en Colombia: "La Fiscalía ha recibido numerosas comunicaciones en virtud del artículo 15 del Estatuto de Roma en relación con la situación en Colombia. 
de civiles organizados por miembros de las fuerzas estatales para que parezcan muertes en combate, conocidos como homicidios por "falsos positivos", los delitos sexuales y de género y el desplazamiento forzado (Oficina de la Fiscalía de la CPI, 2018, p. 36).

El ejercicio de la complementariedad positiva ha tenido un importante papel en el seguimiento del proceso de paz con las FARC, por ejemplo, cuando la Fiscalía de la CPI ha manifestado sus reparos sobre algunos aspectos que regulan el funcionamiento de la JEP, en especial, su inquietud ante una posible interpretación restrictiva del concepto de responsabilidad de mando (Stewart, 2018, p. 9). Esta preocupación también se ha puesto de manifiesto en el Informe sobre las actividades de examen preliminar del 5 de diciembre de 2018, en el que se incluye entre los aspectos evaluados la responsabilidad de mando. Al respecto, la Fiscalía ha enfatizado que “(...) dependerá de los magistrados de la JEP interpretar la legislación nacional vigente y la definición de responsabilidad de comando en particular, teniendo en cuenta cómo se ha desarrollado la noción de responsabilidad de mando en la ley internacional" (2018, p. 41). De este modo, en caso de que el artículo 24 del Acto Legislativo se aplique de tal manera que permita que las personas de alto rango eludan su responsabilidad penal por los crímenes cometidos por sus subordinados, esta situación podría dar lugar a que el examen preliminar de la situación de Colombia se extienda sobre aquellos casos en los que los superiores de alto rango no son llevados ante la justicia, lo que podría conllevar a la activación de la competencia de la CPI.

En este sentido, la Fiscalía deberá valorar si el Estado ha iniciado procesos que involucren la responsabilidad de los superiores, y si esos procesos son genuinos (disposición para investigar), es decir, si no buscan sustraer a los perpetradores de la responsabilidad penal (Stewart, 2018). Con arreglo al segundo párrafo del artículo 17 del ER los procesos se consideran genuinos si: (i) no han sido adoptados con el propósito de sustraer a la persona de que se trate de su responsabilidad penal; (ii) no han sufrido una demora injustificada en el juicio que sea incompatible con la intención de hacer comparecer a la persona ante la justicia; y (iii) se han sustanciado

El examen preliminar se centra en los presuntos crímenes de lesa humanidad y los crímenes de guerra cometidos en el contexto del conflicto armado entre las fuerzas gubernamentales, los grupos armados paramilitares y los grupos armados rebeldes, incluidos los crímenes de lesa humanidad de asesinato; traslado forzoso de población; encarcelamiento u otra privación severa de la libertad física; tortura; y la violación y otras formas de violencia sexual; y los crímenes de guerra de asesinato; ataques intencionales contra civiles; tortura; otro trato cruel; atropellos a la dignidad personal; toma de rehenes violación y otras formas de violencia sexual; y utilizar a los niños para participar activamente en las hostilidades. El examen preliminar también se centra en la existencia y la autenticidad de los procedimientos nacionales en relación con estos delitos" (Corte Penal Internacional, [en línea]). 
de manera independiente o imparcial de forma que sea compatible con la intención de hacer comparecer a las personas ante la justicia. Por ende, el examen de admisibilidad por la indebida aplicación de la responsabilidad de mando estará supeditada a la evaluación de las circunstancias descritas y requerirá de un análisis cuidadoso del tratamiento que la JEP haga de estos casos, lo que podría tomar años. De forma alternativa, en función de la llamada jurisdicción universal ${ }^{36}$ los jueces de otros países podrían juzgar a los máximos responsables que logren sustraerse de responsabilidad penal por una aplicación de la figura de responsabilidad de mando que sea contraria a los estándares internacionales; ${ }^{37}$ sin embargo, siguiendo los ejemplos en los que se ha intentado aplicar esta figura, el juzgamiento de un mando militar o guerrillero por jueces de otros países es una posibilidad remota y supone complejos debates a nivel judicial, político e incluso académico.

Sobre la base del carácter de estos dos mecanismos de justicia (CPI y jurisdicción universal), resulta entonces esencial que la JEP, como primera llamada a luchar contra la impunidad de los crímenes cometidos durante el conflicto armado, interprete $\mathrm{y}$ aplique adecuadamente la responsabilidad de mando frente a las altas esferas de la cadena de mando militar y guerrillero, con el fin de que la intervención de la CPI no vaya más allá del ejercicio de la complementariedad positiva. Para ello será necesaria la armonización de la definición del artículo 24 con el DIC y el DIP no solo por razones de justicia con las víctimas, sino también para dar solidez jurídica y legitimidad al proceso de paz.

Con el fin de establecer algunos límites al proceso de armonización, es necesario analizar la interpretación de la figura de responsabilidad de mando efectuada por la Corte Constitucional. En la Sentencia C-674 de 2017, el Tribunal ejerció el control de constitucionalidad del Acto Legislativo 01 del 2017, evaluando inter alia el concepto de responsabilidad de mando del artículo 24. Sobre este particular, la Corte concluyó que la redacción de este artículo resulta constitucional, pues no comporta una sustitución del deber del Estado de investigar, juzgar y sancionar a los máximos

36 Véase: ASAmblea General, "Texto de los Principios de Princeton sobre la Jurisdicción Universal", Documento de las Naciones Unidas, A/56/677, 4 de diciembre de 2001. En términos semejantes, la Resolución adoptada por el Instituto de Derecho Internacional en Cracovia, el 26 de agoosto de 2005. TOMUSCHAT, C., "La compétence universelle en matière pénale à l'égard du crime de ģénocide, des crimes contre l'humanité et des crimes de ģuerre", en Annuaire de l'Institut de droit international, Vol. 71-I, 200 ha denominado como "complementariedad horizontal". El propósito de introducir complementariedad en las relaciones interestatales es fomentar procedimientos nacionales genuinos en el estado que mejor se adapten a los delitos y evitar afirmaciones demasiado amplias de la jurisdicción universal" (Traducción propia). Bero̧smo M., en Complementarity and the Exercise of Universal Jurisdiction for Core International Crimes. 
responsables de las graves violaciones a los derechos humanos. Al respecto, la Corte afirmó que:

(...) el punto relevante y decisivo desde la perspectiva del juicio de sustitución no es si la figura de la responsabilidad de mando fue delineada en los términos más estrictos posibles, si amplió los dispositivos de la responsabilidad penal a sus más amplias posibilidades, o si reprodujo la fórmula del Estatuto de Roma, sino si alguna de estas circunstancias deviene en la anulación de la prohibición general de la impunidad, que constituye precisamente el elemento definitorio de la Carta Política que le corresponde preservar a este tribunal, y dentro del cual el constituyente secundario contaba con un amplio margen de maniobra (margen de apreciación) para configurar las estructuras de imputación penal..$^{38}$

Partiendo de este punto, la Corte Constitucional equipara la figura de responsabilidad de mando con la responsabilidad penal de los máximos responsables, al puntualizar que las estructuras generales de imputación penal que prevé el derecho interno "[...] pueden ser utilizados para investigar, juzgar y sancionar a los máximos responsables de los crímenes más graves y representativos cometidos en el marco del conflicto armado". Con ello, desconoce que los máximos responsables no siempre son los mandos militares o guerrilleros y que, los títulos de imputación como el de omisión impropia o comisión por omisión no se ajustan a la naturaleza de la responsabilidad de mando, puesto que lo que se castiga no son los delitos de base que le serían atribuidos por no evitar un resultado que tendría el deber jurídico de evitar como garante, sino que la responsabilidad se sustenta en el incumplimiento de un deber de control de los subordinados ${ }^{39}$ (Kai Ambos, 2005).

Seguidamente, la Corte agrega que, si bien el artículo 24 no coincide en su integridad con la formulación de responsabilidad de mando que se encuentra en el Estatuto de Roma, “[...] es claro que la fórmula del artículo 24 apunta al mismo

38 Ver: Corte Constitucional. Sentencia C-674 de 2017. Maģistrado Ponente: Luis Guillermo Guerrero Pérez. Punto 5.5.1.6.

39 Respecto a esta confusión, Olasolo ha señalado que “(...) la comisión por omisión u omisión impropia no se ajusta a la auténtica naturaleza de la RespSup en el art. $28 \mathrm{ECPI}$, puesto que esta última se configura como (i) una complicidad por omisión en el caso del incumplimiento del deber de prevenir; y (ii) un delito de omisión propia en el caso del incumplimiento de los deberes de reprimir y enviar el asunto a las autoridades competentes. En consecuencia, la comisión por omisión, además de no ser aplicable con respecto al incumplimiento de estos dos últimos deberes, exiǵe como forma de autoría unos requisitos objetivos y subjetivos que no se encuentran en la RespSup por omisión del deber de prevenir. Así, en el plano objetivo requiere un vínculo de causalidad con los delitos de los subordinados, consistente en una 'cláusula de equiparación"' (2018, p. 478). 
fenómeno del derecho internacional, y que las diferencias versan sobre el alcance específico de algunos de los criterios de valoración para determinar la configuración de la figura, y no sobre sus elementos estructurales" (2017). La Corte agrega que el artículo 28 del Estatuto de Roma no contiene títulos directos de imputación, sino que es un "mandado general de criminalización" que se refiere genéricamente a la responsabilidad de quienes tienen el mando y el control efectivo, o la autoridad y el control efectivo, y que se materializa en el derecho interno a través de las diversas estructuras de imputación penal y, en el contexto del conflicto armado, a través del artículo transitorio 24 (2017).

Finalmente, el razonamiento del tribunal constitucional sugiere que la fórmula del artículo 24 es mucho más concreta y amplia que la del artículo 28 del Estatuto de Roma, aduciendo que:

(...) el artículo 28 del Estatuto de Roma se refiere genéricamente a la responsabilidad de quienes tienen el mando y el control efectivo, o la autoridad y el control efectivo, mientras que el artículo transitorio 24 no solo introduce la exigencia anterior, sino que además especifica los criterios de valoración de este requisito en el escenario de la fuerza pública, determinando que las conductas punibles deben haber sido cometidas dentro del área de responsabilidad asignada a la unidad bajo el mando del implicado, y que éste debe tener la capacidad legal y materia para emitir órdenes, de modificarlas y de hacerlas cumplir, así como la capacidad efectiva de desarrollar y ejecutar operaciones donde se cometieron los delitos, y de tomar medidas adecuadas para evitar o reprimir la conducta punibles de los subordinados. De igual modo, el artículo 28 del Estatuto de Roma se refiere al elemento subjetivo exigiendo que el superior debe "haber sabido o, en razón de las circunstancias del momento, hubiere debido saber que las fuerzas estaban cometiendo esos crimenes o se proponían cometerlos", mientras que la fórmula del artículo transitorio 24 coincide con la fórmula del Protocolo I adicional a la Convención de Ginebra, ya que la alusión al "conocimiento actual o actualizable" como requisito para la configuración de la responsabilidad, debe ser interpretada en concordancia con la exigencia del mismo precepto sobre la necesidad de que el superior cuente con "información a su disposición, antes, durante o después de la realización de la respectiva conducta". Y mientras el artículo transitorio 24 se refiere al control efectivo sobre 
la conducta delictiva del subordinado, el Estatuto de Roma exige el control general sobre el subalterno (Corte Constitucional, 2017).

Como puede advertirse, la Corte Constitucional concluye que el artículo 24 transitorio recoge los elementos básicos de la responsabilidad de mando y que las diferencias entre su redacción y las disposiciones de derecho internacional no implican una anulación del deber del Estado de investigar, juzgar y sancionar las graves violaciones a los Derechos Humanos y las infracciones al Derecho Internacional Humanitario, pues en escenarios de transición este deber podría contraerse a los máximos responsables, lo que según la Corte no ocurre necesariamente cuando se aplica la figura de responsabilidad de mando.

Con esta sentencia, la Corte ignora los posibles efectos que esta interpretación tenga en la práctica judicial, ya que afirma que el concepto de responsabilidad de mando incorporado en el artículo 24 es constitucional, lo que autoriza en cierta medida su interpretación literal y que, en consecuencia, se produzcan los efectos restrictivos a la hora de efectuar un juicio de atribución de responsabilidad penal. Adicionalmente, la interpretación de la Corte Constitucional parece concebir a los "máximos responsables" como un título de imputación de responsabilidad equiparable al de responsabilidad de mando, lo que se configura como un yerro jurídico que abre la puerta a que se transgreda la prohibición de la impunidad y, en consecuencia, se produzca un efecto contrario a los postulados fundantes de la Constitución Política.

En este sentido, la declaración de exequibilidad del artículo 24 y la interpretación que la Corte hace de la figura de responsabilidad de mando podría ser el primer obstáculo hacia la armonización de la definición contenida en el artículo 24 con los estándares del DIC y el DIP, puesto que, desde una perspectiva teórica, resulta contradictorio que el ejercicio del control de constitucionalidad por vía de excepción contradiga un pronunciamiento de la Corte Constitucional.

Sin embargo, teniendo en cuenta que el Acto Legislativo 01 de 2017, al reformar la Carta Política y ser expedido mediante el Procedimiento Legislativo Especial para la Paz tiene un control de constitucionalidad de naturaleza jurisdiccional, único, automático, participativo, limitado y posterior, la Corte estaba habilitada únicamente para revisar los requisitos especiales que introduce el Acto Legislativo 01 de 2017 referentes a la conexidad material, conexidad teleológica, habilitación temporal y habilitación competencial, así como los vicios de procedimiento ${ }^{40}$ en

40 La Corte Constitucional ha entiendo la revisión de los vicios de procedimiento como el análisis de los requisitos formales para la expedición los actos de reforma constitucional, tales como: (i) la publicación del proyecto en la Gaceta del Congreso, antes de darle curso en la comisión competente; (ii) la forma como 
la formación del Acto Legislativo, no para examinar su contenido material. No obstante, en el caso particular del artículo 24 transitorio, la sentencia pareciera ir más allá, puesto que, a pesar de aclararse que el juicio de sustitución no implica un control material de la legislación, la evaluación efectuada por la Corte delimita el alcance y contenido del artículo 24 en relación con algunos parámetros del derecho internacional.

En este sentido, a pesar de que la Sentencia C-674 de 2017 hizo tránsito a cosa juzgada constitucional absoluta, en su evaluación formal, ello no impide que los magistrados de la JEP, amparados en la autonomía judicial, puedan apartarse de los efectos que dicho juicio implica en relación con el contenido material del artículo $24{ }^{41}$ ejerciendo un control de constitucionalidad por vía de excepción.

Sin embargo, considerando que la excepción de inconstitucionalidad ${ }^{42}$ se aplica en caso de contradicción entre una norma de rango legal y otra de rango constitucional, en el caso del Acto Legislativo 01 de 2017 resulta problemático inaplicar una norma que tiene jerarquía superior (artículo 24) que las normas que podrían sustituir su aplicación como es el caso del artículo 67 del PLE, cuyo rango sería legal y no constitucional. Por otra parte, la aplicación preferente de las normas de DIH y DPI que integran el Bloque de Constitucionalidad, también resulta compleja, ya que se trataría de un conflicto entre normas que ostentan la misma jerarquía, y que, además, no han sido reconocidas expresamente como normas que se integren el Bloque de Constitucionalidad, tal como el artículo 28 del Estatuto de Roma.

se convoca a sesiones extraordinarias; (iii) la acumulación de proyectos; (iv) la designnación de ponentes; (v) la elaboración y publicación de los informe de ponencia; (vi) el anuncio previo de votación; (vii) el sistema y la forma como se surte dicha votación; (viii) la publicación de los textos definitivos en cada una de las Cámaras; (ix) la práctica de las audiencias públicas; (x) el tiempo transcurrido entre primer y segundo debate; (xi) la fase conciliación; (xii) los principios de consecutividad, identidad flexible y unidad de materia; y (xiii) la consulta previa, cuando se incluyan medidas que tengan la posibilidad de afectar directamente a las comunidades indígenas o pueblos tribales. El control de constitucionalidad de los actos reformatorios de la Constitución incluye también un análisis de la existencia de posibles vicios de competencia, lo que ocurre cuando sustituyen la Carta en vigor o reemplazan uno de sus ejes definitorios, al punto de que el Texto Superior pierde, en todo o en parte, la identidad que le es propia. Al respecto ver: Corte Constitucional, sentencias C-551 de 2003, C-1200 de 2003, C-1124 de 2004, C-1040 de 2005, C-472 de 2006, C-740 de 2006, C-153 de 2007, C-1058 de 2008, C-288 de 2012, C-094 de 2017 y C-332 de 2017.

41 En la Sentencia C-836 de 2001, la Corte Constitucional definió que en el sistema jurídico colombiano existe un sistema flexible de precedentes, en virtud del cual los jueces, si bien tienen el deber prima facie de respetar el precedente propio (horizontal) y el de los órģanos de cierre (vertical), pueden también apartarse de esas decisiones judiciales.

42 "La excepción de inconstitucionalidad es una facultad o posibilidad (o si se quiere, una herramienta) de los operadores jurídicos, en tanto no tiene que ser aleģada o interpuesta como una acción; pero se configura iģualmente como un deber en tanto las autoridades no puede dejar de hacer uso de ella en los eventos en que detecten una clara contradicción entre la disposición aplicable a un caso concreto y las normas constitucionales". Corte Constitucional, Sentencia SU 132/13 y la Sentencia T- 681 de 2016. 
Ahora bien, a pesar de que la Corte solo ha admitido la inclusión de algunas disposiciones del Estatuto de Roma en el bloque de constitucionalidad, ${ }^{43}$ el tribunal ha empleado otras de sus disposiciones como parámetros de interpretación y adecuación de la legislación interna, y no ha negado la posibilidad de que puedan ser incorporados a la Constitución. ${ }^{44}$ Siguiendo el precedente constitucional, es dable afirmar que la incorporación de un artículo del Estatuto de Roma en el Bloque de Constitucionalidad corresponde a un desarrollo jurisprudencial que ha surgido del estudio de casos, ya que según la postura de la Corte "(...) hacen parte del bloque de constitucionalidad aquellos instrumentos de Derecho Penal Internacional aprobados por Colombia, que guardan una relación directa con la protección de los Derechos Humanos y del Derecho Internacional Humanitario, lo que desde luego deberá ser examinado caso a caso" ${ }^{\$ 5}$ (2009). Esto implica que el artículo 28 del Estatuto de Roma eventualmente pueda ser incorporado en el Bloque de Constitucionalidad, teniendo en cuenta su conexidad con los derechos de las víctimas y con los postulados esenciales de la Carta Política.

Por otra parte, el Estatuto de Roma ha permitido reforzar la argumentación del juez constitucional (Corte Constitucional, 2012), por lo que en ciertos casos ha operado un reenvío hacia el Estatuto de Roma, con el fin de dotar de contenido y alcance una determinada expresión legal, tal y como ha sucedido con los crímenes de guerra ${ }^{46}$ (Corte Constitucional, 2002). Específicamente, en el caso del artículo 28 del ER, la Corte ha traído a colación su texto para extender y armonizar el

43 No todo el Estatuto de Roma hace parte del bloque de constitucionalidad. La Corte Constitucional ha estimado que no todo el texto del Estatuto de Roma hace parte del bloque de constitucionalidad, lo cual no obsta para que algunos de sus artículos sí lo conformen. En tal sentido, de manera puntual, han sido tomados como parámetros para ejercer el control de constitucionalidad las siguientes disposiciones: el Preámbulo (C-928 de 2005); el artículo 6, referido al crimen de genocidio (C- 488 de 2009); artículo 7, relacionado con los crímenes de lesa humanidad (C- 1076 de 2002); artículo 8, mediante el cual se tipifican los crímenes de guerra (C- 291 de 2007, C-172 de 2004 y C- 240 de 2009); el artículo 20, referido a la relativización del principio de la cosa juzģada (C- 004 de 2003 y C- 871 de 2003), al iģual que los artículos 19.3, 65.4, 68, 75 y 82.4, concernientes a los derechos de las víctimas (C- 936 de 2010). Corte Constitucional, Sentencia C-290 de 2012.

44 Al respecto, la Corte Constitucional “(...) ha preferido determinar, caso por caso, qué artículos del Estatuto de Roma, y para qué efectos, hacen parte del bloque de constitucionalidad". (Corte Constitucional, Sentencia C-290 de 2012).

45 Ver: Corte Constitucional, Sentencia C- 488 de 2009.

46 En la sentencia C-1076 de 2002, la Corte recurrió al texto del Estatuto de Roma con un doble objetivo: (i) examinar la validez de una norma leģal, es decir, tomarlo realmente como parámetro para ejercer el control de constitucionalidad, más exactamente, su artículo 8, y (ii) a efectos de dotar de contenido un tipo disciplinario abierto o en blanco, con el fin de poder luego confrontar la norma legal con la Constitución. 
alcance de disposiciones de derecho interno, por ejemplo, en la sentencia SU- 1184 de $2001^{47}$ y en la sentencia C- 181 de $2002 .^{48}$

En este sentido, una solución más pacífica consiste en la aplicación del ER como parámetro de control de constitucionalidad y de adecuación del artículo 24 del Acto Legislativo. Esto significa que los requisitos y expresiones que contiene el artículo 24 del Acto Legislativo que resulten incompatibles con el DPI deberán ser interpretados sobre la base de los estándares que se derivan del ER y otras normas del DIC, acogiendo como criterio hermenéutico la norma más amplia en la protección de Derechos Humanos y en la garantía del DIH (principio pro personae), lo que a su vez permite hacerse en la mayor medida posible a los objetivos teleológicos del Acuerdo de Paz, tales como satisfacer los derechos de las víctimas y lograr una paz duradera y estable.

Sin embargo, esta posición supone ciertas contrariedades con el principio de legalidad y de seguridad jurídica por cuanto implica una interpretación teleológica y no literal del artículo transitorio 24, y por lo tanto la extensión del contenido de una disposición que atribuye responsabilidad penal. En este sentido, la disyuntiva surge por la relación entre la 'responsabilidad de mando' y el 'tratamiento penal diferenciado ${ }^{39}$ para los militares y policías que han participado del conflicto armado, puesto que la adecuación del artículo 24 con el ER, supone un tratamiento penal similar al que reciben los mandos guerrilleros en virtud del artículo 67 del PLE. Por este motivo, detractores como la Asociación Colombiana de Oficiales en Retiro (en adelante "ACORE") argumentan que mantener el sentido del artículo transitorio 24 garantiza el respeto del principio de legalidad como eje central de las garantías judiciales de quienes han servido al país desde las instituciones castrenses y de policía $^{50}(2017 ; 2018)$.

Pese a lo anterior, en un escenario de justicia transicional es usual que intereses como el de la justicia y la paz entren en tensiones insalvables, que requieren de un análisis ponderado e incluso de una delimitación de lo negociado en un Acuerdo

47 La Sentencia se refiere al juzģamiento de miembros de la fuerza pública por la comisión de crímenes internacionales.

48 En este caso en concreto, se trató de examinar la validez de la consagración de la falta disciplinaria de comisión de genocidio, prevista en el literal a) del artículo 25.5 de la Ley 200 de 1995.

49 El tratamiento penal diferenciado se aplicará respecto de los aģentes del Estado que hubieren cometido delitos relacionados con el conflicto armado y con ocasión de este, aplicación que se hará de forma diferenciada, otorgando un tratamiento equitativo, equilibrado, simultáneo y simétrico. En dicho tratamiento deberá tenerse en cuenta la calidad de garante de derechos por parte del Estado, así como la presunción de que el Estado ejerce de manera leớtima el monopolio de las armas. Ver Ley 1820 de 2016 "por medio de la cual se dictan disposiciones sobre amnistía, indulto y tratamientos penales especiales y otras disposiciones".

50 La Asociación Colombiana de Oficiales de las Fuerzas Militares en Retiro (ACORE) en la Sentencia C-007 de 2018 y en la sentencia C-674 de 2017 
de Paz. Bajo esta premisa, resulta esencial determinar el alcance de los derechos de las víctimas en contraposición con las garantías del debido proceso en contexto de transición.

La justicia es concebida como un derecho fundamental de las víctimas, cuyo correlato principal se encuentra en la obligación estatal de investigar, juzgar y sancionar las graves violaciones a los Derechos Humanos y las graves infracciones al Derecho Internacional Humanitario ${ }^{51}$ (Corte Constitucional, 2018). Como ocurre con la paz, la justicia es una condición de validez y un elemento fundante del ordenamiento constitucional; sin embargo, desde las diversas dimensiones iusfundamentales del derecho, esta no es absoluta, y en procesos tan complejos como los de transición, este derecho establece relaciones de interdependencia con otros principios.

En el caso particular de la aplicación del artículo transitorio 24 se generan efectos en doble vía; por un lado, su aplicación materializa la posibilidad de que los responsables de crímenes cometidos bajo esta modalidad puedan ser investigados y juzgados, y por el otro, expone al superior a un juicio de atribución de responsabilidad penal por los delitos de los subordinados bajo su control. Este escenario supone la colisión entre los derechos a la verdad, la justicia y la reparación integral de las víctimas y, las garantías del debido proceso, tales como el principio de legalidad. No obstante, el contenido y alcance de los principios derivados del debido procesal legal difiere en los procesos de justicia transicional, ya que su aplicación no debería impedir la investigación, juzgamiento y la aplicación de sanciones a quienes hayan cometido crímenes durante el conflicto armado.

En contextos de postconflicto, las categorías que componen los mayores atentados contra la dignidad humana han sido decantadas en un proceso histórico a partir del cual se ha construido un consenso internacional en torno a la gravedad de tales conductas, por lo que es exigible tanto a los Estados, como a los grupos armados, pues uno y otros están en capacidad de comprender la existencia de la prohibición (accesibilidad) y de prever que esta acarrea sanciones severas (previsibilidad $)^{52}$ (Olasolo, 2013). En este sentido, no es dable afirmar que los miembros

51 Corte Constitucional. Sentencias C-370 de 2006. MM.PP. Manuel José Cepeda Espinosa, Jaime Córdoba Triviño, Rodriģo Escobar Gil, Marco Gerardo Monroy Cabra, Álvaro Tafur Galvis y Clara Inés Vargas Hernández y C-379 de 2016. M.P. Luis Ernesto Varģas Silva.

52 Los derechos de las víctimas en situaciones de transición, a la verdad, la justicia y la reparación con garantías de no repetición, alcanzaron su positivización constitucional con la reforma efectuada por el Acto Leo̧islativo 01 de 2012, específicamente a través de la adición del artículo 66 Transitorio. Esto, sin embarģo, no permite concluir de manera alguna que con anterioridad a dicha enmienda la Carta no les brindara un sustento claro y decidido, ni que sobre ellos no hubiera ya una jurisprudencia en construcción. También debe advertirse que, antes del anterior referente constitucional, había disposiciones con fuerza de ley incorporadas al ordenamiento jurídico en tal sentido. En la sentencia C-370 de 2006. MM.PP. Manuel José Cepeda Espinosa, Jaime Córdoba Triviño, Rodrigo Escobar Gil, Marco Gerardo Monroy Cabra, Álvaro Tafur 
de la Fuerza Pública se verían sorprendidos por la creación de un tipo penal ex post facto o por el cambio de condiciones para la atribución de responsabilidad penal, puesto que era previsible que la transgresión de los Derechos Humanos y las normas del DIH implicaría la imposición de sanciones, incluso en un sistema jurídico diferente al transicional.

La concepción del principio de legalidad en el derecho interno, que se concreta bajo el aforismo "no hay pena sin ley previa" - nullum crimen sine lege, en el DPI adopta la formulación más amplia que se traduce en "no hay pena sin derecho previo" -nullum crimen sine iure-. Esto se explica por la naturaleza propia de los procesos de creación de normas de Derecho Internacional, y por la interrelación entre las fuentes principales y auxiliares en el ordenamiento jurídico internacional. La complejidad de estos procesos implica la aplicación de los métodos de interpretación jurídica, es decir una labor hermenéutica por parte de los órganos encargados de la aplicación del derecho, con el fin de que el sentido del texto interpretado sea acorde con el conjunto de normas internacionales y guarde coherencia con las demás normas dentro sistema, según una interpretación sistemática. ${ }^{53}$

En Colombia, el proceso penal adelantado por la JEP no busca exclusivamente la imposición de una sanción -justicia retributiva-, sino que parte de un modelo de justicia que tiene como objetivo la reconstrucción del tejido social, la reparación del daño causado y la satisfacción de los derechos de las víctimas justicia restaurativa-. ${ }^{54}$ Desde esta perspectiva, el principio de legalidad puede flexibilizarse y adoptar una fórmula mucho más amplia; teniendo en cuenta, que tanto en el Acto Legislativo 01 de 2017, como en el Acuerdo Final se enfatiza en la centralidad de los derechos de las víctimas, carece de coherencia que se conciba la concesión de beneficios o de un tratamiento penal diferenciado sin condiciones adecuadas para la satisfacción

Galvis y Clara Inés Vargas Hernández, la Corte Constitucional resolvió la demanda de inconstitucionalidad sobre alogunos artículos de la Ley 975 de 2005, por la cual se dictan disposiciones para la reincorporación de miembros de grupos armados organizados al margen de la ley, que contribuyan de manera efectiva a la consecución de la paz nacional y se dictan otras disposiciones para acuerdos humanitarios. En esta oportunidad, la Sala Plena advirtió que, aunque no se hubieran construido estándares sobre los derechos de las víctimas en contextos de transición, sí había fijado varios criterios en el marco constitucional de normalidad, los cuales eran aplicables en este caso, dado que la transición no suspendía la Constitución. Al respecto precisó: "Tales parámetros tienen que ver con los derechos de las víctimas a la justicia, verdad, reparación y no repetición (...) las condiciones en que pueden ser concedidas las amnistías o indultos, la imprescriptibilidad de la acción penal respecto de ciertos delitos, y la necesidad de que ciertos recursos judiciales reconocidos dentro del proceso penal se establezcan no solo a favor del procesado sino también de las víctimas, cuando el delito constituye un grave atentado en contra de los derechos humanos o del derecho internacional humanitario" (Corte Constitucional, 2006). en la Convención de Viena sobre el Derecho de los Tratados en el artículo 31. Reģla ģeneral de interpretación y en el artículo 32. Métodos complementarios de interpretación. 
de los derechos a la verdad, la justicia y la reparación, o en circunstancias que posibiliten sustraer de responsabilidad penal a los perpetradores de graves violaciones a los Derechos Humanos.

En virtud de lo anterior, los magistrados y magistradas de la JEP deberán efectuar una tarea de adecuación entre derecho interno y derecho internacional, lo que demanda que se consulten un conjunto de fuentes que exceden a la ley en sentido formal, con el fin de brindar mayor solidez y eficacia al proceso de implementación del Acuerdo de Paz, ya que de aplicarse una interpretación literal del artículo transitorio 24 podrían presentarse escenarios, en los que, en virtud de garantías procesales como principio de favorabilidad penal, los mandos guerrilleros reclamen la aplicación del artículo 24 por resultar procesalmente más favorable que el artículo 67 del PLE, lo que también amenaza la coherencia interna del sistema y el postulado de 'tratamiento penal diferenciado' aplicable únicamente a los mandos militares. En circunstancias como las analizadas, y con el fin de evitar que el concepto de responsabilidad de mando resulte excesivamente restrictivo o produzca efectos adversos para el cumplimiento de los objetivos centrales del Acuerdo Final, se requiere armonizar algunos apartados del artículo 24 transitorio con los estándares internacionales, de tal forma que se reduzcan los espacios de impunidad que podrían generarse en aquellos casos en los que se juzgue la responsabilidad del superior, y de este modo, evitar eventuales intervenciones de la CPI o de jueces de otros países en ejercicio de la jurisdicción universal.

\section{Conclusión}

La concepción de responsabilidad de mando en el marco jurídico transicional supone complejos desafíos en relación con la lucha contra la impunidad de los delitos cometidos durante el desarrollo del conflicto armado en Colombia. La redacción del artículo 24 del Acto legislativo 01 de 2017 incorpora algunos apartados que resultan incompatibles con los elementos de la responsabilidad de mando desarrollados en el DPI, lo que podría tener como principal efecto que algunos de los mayores responsables evadan la acción de la justicia y que, en consecuencia, la JEP no cumpla con las expectativas de las víctimas.

Los aspectos que resultan más preocupantes son: (ii) la exigencia de cuatro condiciones concurrentes para probar requisito de control efectivo, lo que es contrario al DIP, según el cual, estas condiciones son parámetros meramente indicativos; (iii) que se estipule que la conducta punible haya sido cometida dentro del área de responsabilidad asignada a la unidad bajo el mando del superior, lo que implica que se excluyan los supuestos en los que los crímenes sean cometidos fuera de 
dicha área, pero bajo control efectivo del comandante; (iv) que se requiera de capacidad legal y además material para imputar responsabilidad en razón de mando, ignorando circunstancias en las que el superior sólo tenga capacidad material; (v) la vaguedad de la expresión "medios a su alcance" lo que puede propiciar la interpretación restrictiva y la ausencia de responsabilidad penal; y (vi) el requerimiento de "conocimiento actual o actualizable", lo que supone desconocer el estándar de conocimiento inferido.

La interpretación literal y por tanto restrictiva de la responsabilidad de mando podría suponer la activación de la competencia de la CPI e incluso, así sea como una opción remota, la intervención de jueces de otros países amparados en la jurisdicción universal. Por ello es esencial que, al abordar el análisis de los casos sometidos ante la JEP, se adopten criterios hermenéuticos que armonicen el concepto de responsabilidad de mando del Acto Legislativo con los estándares internacionales.

En este punto, tanto el Estatuto de Roma, así como otras normas internacionales que se incorporen al bloque de constitucionalidad servirían parámetros interpretativos para lograr la armonización de los requisitos de la responsabilidad de mando del artículo 24 del Acto legislativo, de modo tal que se aplique la interpretación más amplia y garantista de los derechos de las víctimas, no solo por evitar la intervención de la CPI, sino por razones de justicia y legitimidad del proceso de paz.

\section{Referencias}

Acevedo, J. (2007). La responsabilidad del superior 'sensu estricto' por crímenes de guerra en el Derecho Internacional Contemporáneo. Revista International Law, volumen (10), 153-198.

Ambos, K. (26 de septiembre de 2015). “¡Tanta justicia sí permite la paz!”. El Espectador. Recuperado de http://www.elespectador.com/opinion/tanta-justicia-si-permite-paz

Ambos K. (1999). La responsabilidad del superior en el Derecho penal internacional. Anuario de Derecho Penal y ciencias penales. (52), pp. 527-593

Ambos, K. (15 de junio de 2018). La absolución de Jean Pierre Bemba y la responsabilidad del Superior. Semana. Recuperado de https://www.semana.com/ opinion/articulo/la-absolucion-de-jean-pierre-bemba-y-la-responsabilidad-del-superior-columna-de-kai-ambos/571182

Ambos, K. (2005). La parte general del Derecho Penal Internacional: Bases para una elaboración dogmática. E. Malarino (trad.), Ed. Duncker y Humboldt, Konrad Adenauer Stiftung y Ed. Temis, Montevideo, 2005, p. 298-299. 
Bergsmo, M. (ed.). (2010). Complementarity and the exercise of universal jurisdiction for Core International Crimes. Oslo: Torkel Opsahl Academic EPublisher. Recuperado de https://www.fichl.org/fileadmin/fichl/documents/FICHL_7_ Web.pdf

Boas, G., Bischoff, J.L., \& Reid, N. (2008). International criminal law practitioner library: Forms of responsibility in International Criminal Law (Volume 1). Nueva York: Cambridge University Press.

Case Matrix Network. (2016). International Criminal Law Guidelines: command responsibility (2a edición). Brussels: Editor Centre for International Law Research and Policy.

CICR. (2001). Comentario del Protocolo adicional I a los Convenios de Ginebra de 1949. Comentario del Protocolo del 8 de junio de 1977 adicional a los Convenios de Ginebra del 12 de agosto de 1949 relativo a la protección de las víctimas de los conflictos armados internacionales (Protocolo I)

Fenrick, W. J. et al. (2008). Part 2. Jurisdiction, admissibility and applicable law: Article 8, War Crimes. En Otto Triffterer, Commentary on the Rome Statute of the International Criminal Court: Observers' Notes, Article by Article (pp. 305-306). Munich, Oxford/Baden-Baden.

Klamberg, M. (ed.). (2017). Commentary on the Law of the International Criminal Court. Bruselas: Torkel Opsahl Academic E Publisher. Recuperado de https:// www.legal-tools.org/doc/aa0e2b/pdf/

Kiss, A. (2016). La responsabilidad penal del superior ante la Corte Penal Internacional. La Haya, Holanda. Recuperado de http://zis-online.com/dat/artikel/2016_1_978.pdf

Lam, J. (2014). Contrasting Complementarity: Assessing the International Criminal Court's Support for Domestic Prosecutions. En International Criminal Justice: The ICC and complementary. Nairobi: The Kenyan Section of the International Commission of Jurists.

Meloni, C. (ed.). (2015). The evolution of Command Responsibility in International Criminal Law. En Morten Bergsmo, CHEAH Wui Ling, SONG Tianying and YI Ping (eds.). Historical Origins of International Criminal Law (Volumen 3) pp. 683-714. Brussels. Torkel Opsahl Academic EPublisher. 
Olasolo, H., \& Canosa, J. (2018). La Responsabilidad del Superior en el Acuerdo de Paz en Colombia a la luz del Derecho Internacional. Política criminal, 13(5), 444-500. Recuperado de http://www.politicacriminal.cl/Vol_13/n_25/Vol13N25A12.pdf

Olasolo, H. (2014). Los exámenes preliminares de la Corte Penal Internacional en América Latina: el caso colombiano y su impacto sobre futuras negociaciones de paz en la región. Anuario de Derechos Humanos, (núm. 10), pp. 35-56.

Olasolo, H. (2013). Tratado de autoría y participación en Derecho Penal Internacional. Valencia: Tirant lo Blanch.

Olasolo, H. (2012). El principio de complementariedad y las estrategias de actuación de la corte penal internacional en la fase de examen preliminar: ¿por qué la corte penal internacional mantiene su examen preliminar, pero no abre una investigación, sobre la situación en Colombia? Revista Electrónica de Estudios Internacionales, Vol. 7 (núm. 24), 79-102. Recuperado de http://repository. urosario.edu.co/bitstream/handle/10336/18479/16.pdf?sequence=1\&isAllowed $=\mathrm{y}$

Olasolo, H. (ed.). (2011). Ensayos de Derecho Penal y Procesal Internacional. Valencia, España: Editorial Tirant lo Blanch \& Instituto Ibero-Americano de la Haya (IIH).

Henckaerts J., \& Doswald-Beck L. (ed.) (2007). El Derecho Internacional Humanitario Consuetudinario (Volumen I). Buenos Aires: CICR.

Olasolo, H. (2007). De los Riesgos y las Precauciones necesarias en la Aplicación del Principio de Complementariedad por la Corte Penal Internacional: El Estudio de la Determinación de las Penas como Objeto de Análisis de Admisibilidad. Revista brasileira de ciências criminais, (núm 67), 59-112

Olasolo, H. (2013). El principio nullum crimen sine iure en el Derecho Internacional Contemporáneo", Bogotá. Anuario Ibero-Americano de Derecho Internacional Penal, ANIDIP, vol. 1, pp. 18-42.

Stahn, C. (2019). Critical introduction to international criminal law. Nueva York: Cambridge University Press.

Uprimny, R. (19 de noviembre de 2016). Un acuerdo sobre el acuerdo. El Espectador. Recuperado de http://www.elespectador.com/opinion/un-acuerdo-sobre-elacuerdo 
Uprimny, R., \& Guiza, D. (2017). Reflexiones sobre la reforma constitucional que crea la Jurisdicción Especial para la paz y regula el tratamiento especial a la Fuerza Pública. Centro de Estudios de Derecho, Justicia y Sociedad (Dejusticia). Recuperado de https://www.dejusticia.org/wp-content/uploads/2017/04/ fi_name_recurso_909.pdf

Vivanco, J. (25 de noviembre de 2016). "Decepcionado" por cambio en Acuerdo de Paz. El Tiempo. Recuperado de http://www.eltiempo.com/politica/proceso-de-paz/vivanco-esta-decepcionado-por-cambio-en-acuerdo-final/16759214\#sthash.ZoWnDHKW.dpuf

Werle, G. (2011). Tratado de Derecho Penal Internacional (Segunda edición). Valencia, España: Editorial Tirant lo Blanch.

Wu, T., \& Kang, Y. (1997). Criminal liability for the actions of subordinates: The doctrine of command responsibility and its analogues in United States. Harvard International Law Journal, Vol (38), pp. 272-297.

\section{Otras fuentes}

Oficina del Alto Comisionado para la Paz, Acuerdo sobre las Víctimas del Conflicto: "Sistema Integral de Verdad, Justicia, Reparación y No Repetición", incluyendo la Jurisdicción Especial para la Paz; y Compromiso sobre Derechos Humanos, 15 de diciembre de 2015. Recuperado de http://www.altocomisionadoparalapaz.gov.co/mesadeconversaciones/PDF/borrador-conjunto-acuerdo-sobre-las-victimas-del-conflicto-1450190262.pdf

Acuerdo Final para la Terminación del Conflicto y la Construcción de una Paz Estable y Duradera, del 12 de noviembre de 2016.

Acuerdo sobre las Víctimas del Conflicto, Borrador Conjunto de 15 de diciembre de 2015: "Sistema Integral de Verdad, Justicia, Reparación y No Repetición”, incluyendo la Jurisdicción Especial para la Paz; y Compromiso sobre Derechos Humanos.

Comunicado conjunto \#7 del 24 de noviembre de 2016, en el que las Delegaciones del Gobierno Nacionaly de las FARC-EP. FE DE ERRATAS. Recuperado de http:// www.altocomisionadoparalapaz.gov.co/mesadeconversaciones/PDF/comunicado-conjunto-7-fe-de-erratas-24-de-noviembre-de-2016-1480001802. pdf 
Stewart, J. (1 de noviembre de 2018). El artículo 28 del Estatuto de Roma. Conferencia llevada a cabo por la Cámara de Comercio de Bogotá, Colombia - conferencia. Recuperado de https://www.icc-cpi.int/itemsDocuments/20181102-dp-bogota.pdf

Stewart, J. (30 de mayo de 2018). El rol de la CPI en el proceso de justicia transicional en Colombia”. Conferencias organizadas por el Instituto Max-Planck de Derecho Público Comparado y Derecho Internacional en Friburgo, la Universidad Externado en Bogotá, y la Universidad EAFIT en Medellín y Bogotá, Colombia.

Fiscalía de la CPI. (2003). Informal Expert Paper: The Principle of Complementarity in Practice, 2003, pág. 30.

Fiscalía de la CPI. (2016). Informe sobre Exámenes Preliminares, situación en Colombia, párr. 257 Recuperado de https:/www.icc-cpi.int/iccdocs/otp/161114-otp-repPE-Colombia.pdf

Bensouda, F. (2017). Escrito de amicus curiae de la fiscal de la Corte Penal Internacional sobre la jurisdicción especial para la paz Ante la Corte Constitucional de la República de Colombia Referencia: RPZ-0000001 y RPZ-003. Recuperado de http://cr00.epimg.net/descargables/2017/10/21/17135b6061c7a5066ea86fe7e37ce26a.pdf?int=masinfo

Fiscalía de la CPI. Prosecutorial Strategy 2009 - 20121 February 2010 The Hague. The office of the prosecutor, ICC. Recuperado de https://www.icc-cpi.int/ nr/rdonlyres/66a8dcdc-3650-4514-aa62-d229d1128f65/281506/otpprosecutorialstrategy20092013.pdf

Fiscalía dela CPI.(2018). Informe sobrelas actividades de examen preliminar de Colombia. Recuperado de https://www.icc-cpi.int/itemsDocuments/2018-otp-rep-PE-Colombia.pdf

\section{Jurisprudencia}

Corte Suprema de Justicia de los Estados Unidos. (1946). Sentencia en el Caso Yamashita, 327 U.S, 4 de febrero de 1946, p. 14.

TPIY. Fiscal c. Čelebići. (2001). (Sentencia de apelación), 20 de febrero de 2001, parág. 192. 
TPIY. Mucic et al. (“Celebici”), TC. (1998). Sentencia en el caso No. IT-96-21-T, 16 de noviembre de 1998, parág. 226.

TPIR. Bagilishema. (2001). TC I, Judgement, Case No. ICTR-95-1A-T, 7 de junio de 2001, parág. 4 .

TIPY. Fiscal vs. Zejnil Delalić, Zdravko Mucić alias “Pavo”, Hazim Delić, Esad Landžo alias “Zenga” (Čelebići). (1998). Caso No IT-96-21-T. Sentencia del 16 de noviembre de 1998.

TPIY. Oric, TC II, Judgement. (2006). Case No. IT-03-68-T, 30 de junio de 2006, parág. 300.

TPIY. Halilovic, AC, Appeal Judgement. (2008). Case No. IT-01-48-A, 16 de octubre de 2007, parág. 63; confirmada en TPIY, Oric, AC, Appeal Judgement, Case No. IT-03-68-A, 3 de julio de 2008, parág. 177.

CPI. The Prosecutor v. Jean-Pierre Bamba Gombo. (2009). Caso N01/01-05/08. Decision on Sentence pursuant to Article 76 of the Statute. Párr. 16. (2016) Decisión de confirmación de cargos, ICC-01/05-01/08-424, The Prosecutor v. Jean-Pierre Bemba Gombo, Sala de Cuestiones Preliminares II, Corte Penal Internacional, 3 de julio de 2009, párrs. 436-442.

CPI. Fiscal c. Bemba. (2016). Decisión con arreglo al Artículo 74 del Estatuto, ICC-01/05-01/08, (Sentencia de primera instancia), 21 de marzo de 2016, parágs. $184,189$.

Corte Constitucional de Colombia. (2002). Sentencia C-578 de 2002. Magistrado Sustanciador: Manuel José Cepeda Espinosa. Referencia: Expediente LAT-223, 30 de julio 2002.

Corte Constitucional de Colombia. (2012). Sentencia C-290 de 2012. Magistrado Sustanciador: Humberto Antonio Sierra Porto. Referencia: Expediente D- 8776, 18 de abril 2012.

Corte Constitucional de Colombia. (2016). Sentencia C-674 de 2016. Magistrado Sustanciador: Luis Guillermo Guerrero Pérez, Referencia: Expediente RPZ-00. 14 de noviembre de 2017.

Corte Constitucional de Colombia. (2018). Sentencia C-080 de 2018. Magistrado Sustanciador: Antonio José Lizarazo Ocampo. Referencia: Expediente RPZ-010, 15 de agosto 2018. 
Corte Constitucional de Colombia. (2018). Sentencia C-007 de 2018. Magistrada Sustanciador: Diana Fajardo Rivera. Referencia: Expediente RPZ-010, 1 de marzo 2018.

\section{Disposiciones jurídicas y normas internacionales}

Acto Legislativo 1 de 2017. (2017). Por medio del cual se crea un título de disposiciones transitorias de la constitución para la terminación del conflicto armado y la construcción de una paz estable y duradera se dictan otras disposiciones. Diario Oficial No. 50.196 de 4 de abril de 2017.

Estatuto de Roma de la Corte Penal Internacional. (17 de julio de 1998).

Estatuto del Tribunal Penal Internacional para Ruanda. (8 de noviembre de 1994).

Norma 153 del Derecho Internacional Humanitario consuetudinario del CICR.

Protocolo Adicional I a los Convenios de Ginebra. (12 de agosto de 1949). Relativo a la protección de las víctimas de los conflictos armados internacionales del 8 de junio de 1977.

Protocolo Adicional II a los Convenios de Ginebra. (12 de agosto de 1949) Relativo a la protección de las víctimas de los conflictos armados sin carácter internacional del 8 de junio de 1977.

Proyecto de Ley número 008 de 2017. (2017). Senado - 016 de 2017 Cámara, "Estatutaria de la Administración de Justicia en la Jurisdicción Especial para la Paz". Recuperado de http://www.corteconstitucional.gov.co/comunicados/ No.\%2032\%20comunicado\%2015\%20de\%20agosto\%20de\%202018.pdf 